\title{
Las cosas del cuerpo en Noches de adrenalina de Carmen Ollé ${ }^{1}$
}

\author{
Biviana Hernández O. \\ Universidad Austral de Chile \\ urganda5@yahoo.es
}

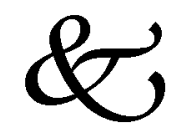

\begin{abstract}
Resumen
En este artículo indagaremos en la escritura de Noches de adrenalina (1981), de Carmen Ollé, atendiendo a su doble articulación del "cuerpo producido" (lo anatómico y lo verbal), como aprendizaje del cuerpo orgánico en su ciclo de cambios (lo fisiológico y psicológico), para analizar de qué manera la poeta construye la anatomía de un cuerpo textual como flujo de pensamiento y reflexión; otra forma de asumir el poder del discurso conforme una subjetividad de mujer, cotidiana y micropolítica. Partimos de la hipótesis del tratamiento estético de la abyección por lo sexual-excrementicio que el poemario desarrolla, de acuerdo con una retórica de la suciedad, junto a la mirada psicoanalítica que resulta de los deseos reprimidos, los complejos de falta y las pulsiones narcisistas del sujeto.

Palabras claves: Carmen Ollé, poesía peruana, anatomía, textualidad, abyección, poder del discurso.
\end{abstract}

\begin{abstract}
In this article, we will inquire into the writing of Noches de adrenalina (1981), of the Peruvian poet Carmen Ollé (1947), attending to its dual articulation of the "produced body" (both, anatomical and verbal) as a learning of the organic body in its cycle of changes (both physiological and psychological), to analyze how the poet builds the anatomy of a textual body as a flow of thought and deliberation; namely, another
\end{abstract}

1 Este artículo forma parte del proyecto FONDECYT de Postdoctorado n 3130628: "Poesía y neovanguardia: textualidades para un nuevo repertorio", del cual soy investigadora responsable. 
way of understanding the power of discourse according to the female's subjectivity, daily and micropolitical. We start from the hypothesis of the abjection's aesthetic treatment through sexual-excremental elements, that the poetry book develops following a rhetoric of dirtiness, along with a psychoanalytical insight which comes by the repressed desire, the lack complex and the narcissist instincts of the subject.

Keywords: Carmen Ollé, peruvien poetry, anatomy, textuality, abjection, power of discourse.

Recibido: 15/7/14 Aceptado: 18/9/14 Publicado on line: 10/2/15

El paisaje de mis días parece estar compuesto, como las regiones montañosas, de materiales diversos amontonados sin orden alguno. Veo allí mi naturaleza, ya compleja, formada por partes iguales de instinto y de cultura. Aquí y allá afloran los granitos de lo inevitable: por doquier, los desmoronamientos del azar. Trato de recorrer nuevamente mi vida en busca de su plan, seguir una vena de plomo o de oro, o el fluir de un río subterráneo, pero este plan ficticio no es más que una ilusión óptica del recuerdo.

M. Yourcenar.

\section{Para comenzar}

Si discurso refiere no solo un objeto de deseo, sino también aquello por lo que se lucha, el poder que se busca poseer (Foucault 1992), resulta notable que en Noches de adrenalina $(1981 / 2005)^{2}$ ese objeto de deseo elabore la perspectiva existencial, intimista y autobiográfica, de una subjetividad de mujer, cotidiana y micropolítica, como posibilidad de articular y detentar un poder; poder de la palabra como agenciamiento estético-político de la escritura, desde donde la poeta va a elaborar el registro de un aprendizaje del cuerpo por sus partes sucias; esas partes que violentan el lenguaje haciendo que este agreda cada vez que se expresa con el cuerpo (con las partes "bajas" del cuerpo, con lo excrementicio y lo sexual), "porque eso es lo que debió excluir para constituirse" (2), asevera Oubiña cuando se refiere a la "boca sucia" de Osvaldo Lamborghini; escritura del mal, en la concepción de Bataille (1977), dentro de ese universo literario que el teórico francés vislumbrara como un territorio que privilegia la transgresión en tanto puede cruzar todos los límites y, en consecuencia, decirlo todo. Y Ollé,

2 Hemos utilizado la versión de 2005, editada en conjunto por el Centro de la Mujer Peruana, Flora Tristán y Lluvia Editores. Otros textos de Carmen Ollé, en poesía, son: Todo orgullo humea la noche (1988), mientras que en narrativa: Por qué hacen tanto ruido (1992), Las dos caras del deseo (1994), Pista falsa (1994), Una muchacha bajo su paraguas (2002) y Retrato de mujer sin familia ante una copa (2007). 
en buena medida, parece querer decirlo todo en relación a ese aprendizaje fisiológico y psicológico de las partes sucias del cuerpo, su cuerpo. Tratándose de un autoanálisis verbal y físico que interroga las vicisitudes del deseo, el placer y sus goces, siempre interrumpidos o inacabados por los complejos de falta, que sintomatizan las patologías del sujeto narcisista, atravesado por la espacio-temporalidad de la memoria y la escritura.

El texto parte de una autoindagación donde el proceso de lectura es determinante, abundando en referencias, citas literarias y teóricas, como un diálogo o monólogo dramático con sus propias fuentes (directas e indirectas), y proponiendo un juego intertextual con varios tipos de transgresiones métricas y formales de linaje vanguardista (Borsò 1998); de donde la relación de la lectura con su cuerpo determinará no solo la autopercepción del cuerpo orgánico como fetiche, sino también de la lectura misma como un proceso indisociable del cuerpo deseante de la escritura:

Las relaciones con las partes de mi cuerpo no son teológicas

son frustraciones, derivadas del dolor de un cuerpo fetiche.

Hoy perdí un diente

¿evacuación de una consciencia sufriente?

Pérdida de rigor:

¿hay algo más honesto que esta ley grave?

¿la belleza de las piezas naturales intactas no es un

humanismo narcisista?

Hoy perdí un diente (y hoy perdí un diente)

Me extravío-

(...)

La impotencia de ligar con el texto proviene

de la práctica erótica mutilada (desempleo sexual)

(19)

Esas relaciones con las partes del cuerpo desocultan la obscenidad del mismo como el proceso de una "doble focalización" del habla, de un "yo-objeto" que se ve "en tanto que visto por los ojos de los otros" (Borsò 1998: 210). Pero también señalan que ese extravío e "impotencia de ligar con el texto", que proviene del "desempleo sexual", son los primeros síntomas de un sujeto melancólico que siente inhibición ante el deseo sexual y el acto creativo; impotencia de toda productividad, en suma. Tratándose de una patología que hace emerger la actitud narcisista de desnudamiento y de éxtasis frente a la propia imagen del cuerpo, la compulsión de mostrar y decirlo todo con el lenguaje de una gramática impura, que en Noches de adrenalina activa la aproximación al deseo ilimitado de la lectura y del propio cuerpo, en el momento de quiebre entre la "infancia mística” y la "adultez erótica" (Villacorta 2008), que marca un periodo 
de aprendizaje cuando la hablante lee a Bataille, y logra atenuar, mediante la lectura, la sensación de cólera e invalidez frente al estereotipo de mujer que le han hecho asumir a fuerza de manipulaciones:

Bataille me gusta. Es alguien que uno puede leer.

(...)

nos habla como un hombre que sufre con la carne chamuscada

por el deseo que es ilimitado

(...)

En él la religiosa arde la religiosa se desviste

como una puta

en algunas sociedades viriles todo se confabula

para que otros hablen de nuestro deseo lo designen

se retuerzan sobre ese "valor-objeto"

y nos definen para siempre inválidas.

(...)

Se crece entre cólera.

(...)

hay para esto masturbaciones secretas que son éxodos

solitarias defenestraciones a la luz de la lámpara

(23)

Si retomamos el pasaje de las Memorias de Adriano, citado al comienzo, podemos decir que en Noches de adrenalina la marca textual de una voz feminizada y un agenciamiento político de mujer, señala la necesidad compulsiva de articular un relato de la experiencia conforme la mirada introspectiva de la mujer poeta, que quiere captar, "en busca de su plan", las grietas por las cuales ha transcurrido el devenir de la existencia en un espaciotiempo marcado por el aprendizaje de su cuerpo en la disyunción limpieza/ suciedad. La voz poética traza el recorrido de una subjetividad elidida entre espacios, tiempos e interlocutores diversos, de acuerdo con la construcción de una autoimagen que busca definir, aunque sea parcial y provisoriamente, una identidad de mujer adulta. Mientras que en el plano de la escritura diseña una textualidad intergenérica para hacerse un cuerpo en la palabra, un espacio de reflexión y pensamiento, siguiendo el aspecto "intelectual”, que Rowe (1996) identifica como una modalidad expresiva de la escritura autobiográfica de Ollé. Por "aspecto intelectual", debe entenderse no solo la incorporación al texto de citas y referencias literarias de variada procedencia, sino también la continua elaboración de manifestaciones abstractas y analíticas, que actúan como "diagnóstico de las condiciones exploradas y como un cuerpo de pensamiento, un espacio por hacerse" (181). En ese auto, el yo consciente de sí mismo, se imbrica con lo bio, la trayectoria vital experimentada por este yo, único y 
singular, de la mujer viajera que se autoindaga mientras escribe su memoria o diario íntimo, y la grafía, la palabra, la escritura misma con que elabora la retórica de la identidad. La cuestión, por tanto, es la de los límites del discurso, el género (en su doble acepción de lo sexual y lo textual), y la propia subjetividad que emerge de este cruce como posibilidad de escribir la experiencia; límites que enfatizan la temible distancia entre el yo que escribe y el yo que ha vivido a partir de una relación de juicio, de evaluación, de autoanálisis, entre lo que ha sido a partir de lo que es, entre la vida que aún sigue siendo una trayectoria, continuidad del yo, y sus posibilidades de representación verbal desde el acto presente, in situ, aquí y ahora de la escritura.

El cuerpo-texto que representa la anatomía-textualidad de Noches de adrenalina está marcado existencialmente por la "herida de una ecuación de belleza”, -“¿Cómo hay que disimular una cicatriz de cesárea?” (30), -que la hablante asume como un complejo de falta (su autoanálisis siempre llega al punto de partida: la fealdad, la vejez, la enfermedad, la neurosis), de donde su cuerpo aparecerá siempre como ese otro-represor que activa la herida en cada mirada, en cada gesto autoperceptivo:

Un cuerpo desnudo

Siento como si me abandonara al sentido de la perfección

La belleza contendría un cúmulo de defectos propicios

Al escándalo:

Un culo demasiado alto para una talla pequeña

Muslos infavorables a sus extremidades posteriores

Un abrirse donde la franja bruna señalara

La mano como un destino mudo

(71)

Pero el gesto no escatima en el uso de la ironía para evidenciar no solo las patologías de una psiquis femenina, sino también el problema de la belleza artificial frente al deterioro natural del cuerpo femenino: ¿cómo hacemos para mantenernos bellas, según los patrones de belleza occidental, sin morbideces, canas, arrugas?, ¿para reproducir el fetiche social del cuerpo joven y lozano pese a la ineluctable degradación del tiempo?. Una de las hipótesis que sostiene Reisz (1996), al respecto, es que la temática predominante dentro del campo poético femenino de los 80 y 90 hispanoamericanos, es el pánico a envejecer y el disgusto con la propia imagen de mujer adulta, que bien responde a unos de los planteamientos, aquí, psicoanalítico, con que podemos leer la construcción de la subjetividad/textualidad de Noches de adrenalina.

Instalada en el umbral anatómico-psicológico de su propio cuerpo, con sus traumas, neurosis, impotencia, deseos reprimidos, y en un lenguaje que intenta captar los intersticios de una espacio-temporalidad dialéctica entre el 
aquí presente con el allá pasado (París-Lima), Ollé insiste en retratar la edad crítica de los 30 años conforme los fluidos del cuerpo -"estallido de pasión en razón de la pérdida/suavidad del ofrecimiento/y rabia” (63)-. El primer poema del libro se plantea como una reflexión en torno a la experiencia vital que este hecho implica:

TENER 30 AÑOS NO CAMBIA NADA SALVO APROXIMARSE AL ATAQUE

cardíaco o al vaciado uterino. Dolencias al margen

nuestros intestinos fluyen y cambian del ser a la nada.

(...)

Tengo 30 años (la edad del stress).

Mi vagina se llena de hongos como consecuencia del

primer parto.

Este verano se repleta de espaldas tostadas en el

Mediterráneo.

El color del mar es tan verde como mi lírica

verde de bella subdesarrollada.

Tal como sugiere Villacorta, los problemas de espacialidad en el poemario radican en la vacilación de un aquí y la imposibilidad de establecer un allí: "la unidad entre aquí-allí, es decir, ese momento en que Lima y París, la infancia y la adultez, se unen para negar sus oposiciones representadas por las barras que separan las palabras. Esta unión es el momento en el que quien habla se posesiona de ese lugar intermedio. Este es el umbral del lenguaje a donde se llega y de donde se debe partir" (2008: 122-123). La espacio-temporalidad que atraviesa el allá del pasado con el aquí del presente, por tanto, va a situar la obsesión de la hablante por capturar el punto exacto de ese umbral:

Dónde está el peso mayor del estar allí

en el estar o en el allí?

En el allí -que sería preferible llamar

un aquí -debo buscar primeramente mi ser?

(15)

Pero identidad y espacio(s) son imposibles de establecer ante el fracaso del anhelo por unir, simultáneamente, dos tiempos y dos lugares, pasado y presente, que, a su vez, remiten a dos tipos de experiencias disímiles; una, irreversible por cuanto señala el lugar de origen, donde están inscritas todas las marcas de la memoria más remota, el nacimiento y la infancia; otra, provisoria en tanto refiere el estado de extranjería o migración de la mujer viajera en su paso por algunos lugares de Europa. Tensiones que inciden, finalmente, en la trágica distancia que percibe la mujer adulta, respecto de la adolescente, en relación con la que se autoanaliza en presente: 
Me doy cuenta que aún persisto en la búsqueda

de unión de dos tiempos:

el adolescente y el ahora

como un detective un perfil que se esfuma

(...)

En una ciudad extranjera

Donde el yo se improvisa como

El único personaje en medio del estado policial

En el sueño soy perseguida por mis privaciones

Secretas

En los subte por los flics

(73)

Ese perfil que se esfuma en la búsqueda infructuosa de la unión de dos espacio-tiempos es, por tanto, el argumento y la justificación del texto en el deseo por articular un discurso (que es tanto objeto de deseo como el poder que se busca poseer), que contenga y a su vez comprima dos tipos de experiencia disímiles pero simultáneas en el momento de la escritura. El yo autobiográfico de Ollé es una ficción atravesada por un principio de improvisación (invención y reconstrucción de la identidad); "el yo se improvisa" (o se performa) en medio de dos evocaciones, donde se confunden sueño y realidad. En el sueño, la hablante se imagina perseguida por sus privaciones, que remiten a sus complejos de falta y patologías neuróticas; mientras que en la realidad es perseguida por el estado policial de una ciudad extranjera, París (en el argot francés, flics quiere decir policías):

Enredada en dos lenguas que poseer

dos ciudades se invierten como

dos torsos imaginarios

una perdida en el ardor de su pasado

otra en el estupor de la madurez (75)

Pero la experiencia de extranjería en Europa, sus pequeñas anécdotas en París o el Mediterráneo, es en realidad una excusa para situar la complejidad psicológica de una mujer en crisis (y también en rebelión), donde ardor y estupor serán los términos que marcarán el quiebre de una psiquis reprimida por los deseos de la infancia-adolescencia. De allí que la experiencia pasada, en su distancia con el tiempo presente, determine la percepción de descalabro en la mirada actual de la adultez o la madurez -"la madurez ha obturado lo que en la adolescencia/era transparente” (77)-. Lo que se ganó antes en la etapa de iniciación a la sexualidad (ardor, pasión, intensidad), se perdería, luego, con la repetición de un gesto, la domesticación de la práctica sexual que llega a convertirse en un mero rito de costumbre: 
¿por qué entonces esta desesperación por alcanzar

el ardor?

y ha de ser impotencia todo lo que hoy no es

posible?

(61)

La desesperación por no alcanzar o capturar ese tiempo del ardor adolescente determina, finalmente, la sensación actual, en la adultez, de impotencia, mas no solo como imposibilidad de deseo y acto sexual, sino también de capacidad creadora; lo que puede asociarse con los síntomas de la melancolía, que Freud asocia al sentimiento de duelo: "desazón profundamente dolida, una cancelación del interés por el mundo exterior, la pérdida de la capacidad de amar, la inhibición de toda productividad y una rebaja en el sentimiento de sí que se exterioriza en autorreproches y autodenigraciones, que se extreman hasta una delirante expectativa de castigo" $(1991: 215)^{3}$.

\section{Autoanálisis y cuerpo mutilado}

Rompiendo con la interdicción que prohíbe a la mujer enfrentar los conflictos de su mundo desde el propio cuerpo (Miranda 2008), la escritura de Ollé reflexiona sobre la porosidad que implica su par semántico, "femenina", cuando hablamos de poesía escrita por mujeres, pues resulta ineludible la marca de género como agenciamiento político de la escritura, además de su inscripción como "poética emergente" dentro del campo cultural y literario peruano de los $80^{4}$. Tratándose de una poética que propone la anatomía como

3 Añade Freud que el duelo muestra los mismos rasgos que la melancolía, excepto uno, "falta en él la perturbación del sentimiento de sí. Pero en todo lo demás es lo mismo (...) El melancólico nos muestra todavía algo que falta en el duelo: una extraordinaria rebaja en su sentimiento yoico $\{$ Ichgefühl\}, un enorme empobrecimiento del yo. En el duelo, el mundo se ha hecho pobre y vacío; en la melancolía, eso le ocurre al yo mismo (...) En el melancólico podría casi destacarse el rasgo opuesto, el de una acuciante franqueza que se complace en el desnudamiento de sí mismo.(...) la disposición a contraer melancolía se remite al predominio del tipo narcisista de elección de objeto (...) la melancolía toma prestados una parte de sus caracteres al duelo, y la otra parte a la regresión desde la elección narcisista de objeto hasta el narcisismo" (1991: 217).

4 Para Morales Saravia (2008), las "poéticas emergentes" realizan una crítica y renovación de las dicciones pertenecientes a las poéticas del "exteriorismo" y la "modernidad", que caracterizan, sobremanera, las tendencias de los años '60 en gran parte de Latinoamérica, inaugurando un nuevo sistema: "renuevan (amplían, complejizan, pluralizan) el arsenal discursivo, elocutivo y comunicativo de los sistemas anteriores" (124). Siendo lo emergente aquello que resulta cuando los principios de una poética "son interpenetrados por otros ajenos que llevan a que la estructura de dicha poética se siga reproduciendo, pero a partir de ese momento en otros términos" (120). Ciertamente, en Ollé sigue vigente la poética conversacional del narrativo-coloquialismo de los años 60 y, quizá también, ciertos giros del "poema integral" 
textualidad (Zapata 2002) al diseñar la arquitectura textual y física de un cuerpo incompleto, "lacerado" o "mutilado". Allí, donde las marcas de una poética que semiotiza en femenino o, parafraseando a Richard (1990), que se construye de acuerdo con un proceso de feminización de la escritura ${ }^{5}$, pero que vale para todo escritor sin distinción de género, connotan la visión de la "mutilación erótica" como un síntoma del grito (aunque el grito, nos decía antes la poeta, sea la figura de la timidez), que la mujer escritora y lectora va modulando conforme se acentúan los síntomas del deterioro físico, pero, sobremanera, según se sitúa un antes y un después que marca la autopercepción del cuerpo y el transcurrir de la vida en él:

Tuve que hablar de la mutilación erótica

Ahora hablo del cuerpo mutilado:

EI INNOMBRABLE

-Perder los miembros y conservar los dientes

qué escarnio- Beckett

(...)

Perder los dientes y no perderlo todo

Perderlo todo y no perder la vida

(...)

Hoy se pierde un diente mañana un ovario

Hoy no ha de durar más que hoy

O mañana a lo sumo un mes.

$(19-20)$

El cuerpo desocultado se expresa en el lenguaje de lo sucio en un proceso de aprendizaje que internaliza la voz poética para el posicionamiento de su autoimagen. Este aprendizaje, que es el de Bataille, como primera fuente de referencialidad y, quizá, más determinante y marcado placer de la lectura, sostiene que la abyección es la incapacidad de asumir con "fuerza suficiente" el acto imperativo de exclusión de las cosas abyectas, valga decir, de las partes

elaborado por Juan Ramírez Ruiz en el contexto de las exploraciones tanto vitalistas como estéticas del grupo Hora Zero (1970), pero su impacto en la escena cultural da un vuelco radical e inaugural (emergente, en el sentido de Morales Saravia) en tanto se trata de una de las voces que abren el repertorio para la poesía de mujeres en el Perú de la época, además de introducir mecanismos hasta ese momento inéditos dentro del campo poético como el uso de lo interartístico y genérico (filiación de poesía y prosa, autobiografía y psicoanálisis), mediante el registro autobiográfico) con recursos de apropiación vanguardista a través de variadas técnicas de inter y transtextualidad (el uso de la cita y la referencialidad, por mencionar solo algunas de las más frecuentes). Cf. Mazzotti y Zapata (1995).

5 Una feminización que se produce cada vez que una poética o una erótica del signo rebalsa el marco de retención/contención de la significación masculina con sus excedentes rebeldes (cuerpo, líbido, goce, heterogeneidad, multiplicidad) para desregular así la tesis normativa y represiva de lo dominante cultural (Feminismo, género y diferencia 18). 
sucias del cuerpo en esta "mística" de hacerlas relato, escritura, de acuerdo con esa conciencia herida de la espacio-temporalidad, que distinguía un ardor pasado, glorioso, frente al estupor invalidante del presente, la madurez. Por eso, "en esta mística de relatar cosas sucias estoy sola y afiebrada" (24), confiesa la hablante, evocando la violencia del sollozo, del vómito, la náusea, protesta muda del síntoma, en sus poderes de la perversión, frente a la (im) posibilidad de relatar esas cosas del cuerpo en relación con los espaciotiempos en que la experiencia se ha fragmentado en un duelo originario (el paso de la adolescencia a la adultez), y que, finalmente, no logra traducir como un relato orgánico de la escritura y la vida. Pero en esa fiebre por decirlo todo, parece replicar las palabras de Kristeva cuando afirmaba que: "esos humores, esta impureza, esta mierda, son aquello que la vida apenas soporta, y con esfuerzo. Me encuentro en los límites de mi condición de viviente. De esos límites se desprende mi cuerpo como viviente. Esos desechos caen para que yo viva, hasta que, de pérdida en pérdida, ya nada me quede, y mi cuerpo caiga entero más allá del límite" (2006: 10). La hablante se encuentra en esos límites de su condición de viviente, cuando sabe que el pasado es irreversible y el presente una carrera contra el tiempo, la inminencia de la vejez y la muerte. Aunque la pérdida (de los dientes, de los ovarios, de la libido), que conlleva a esa sensación de impotencia sexual y creativa, no sea en estricto rigor un origen sublimado de la muerte del sujeto, cuanto experiencia interior de unos límites que reverberan como huellas de un saber y una conciencia trágica de lo temporal y lo espacial, de la vida que ha sido y de la que es a partir de esa relación de juicio, valoración y autopercepción del yo en presente. Esa relación traumática con la propia autopercepción es la que remite a un fuera de sí como a algo que nos limita, "algo "distinto, algo que está fuera del horizonte de nuestra mismidad” (Borsò 1998: 213):

El ardor vivido es una aventura que ha llegado al límite

(...)

esta sensación del límite es precisamente todo

lo que no es límite y vive en nosotros

(59)

Los límites de la infancia, de la adultez, de la psiquis femenina, el aprendizaje del cuerpo, todo queda encapsulado en ese agujero negro del inconsciente y de todo aquello que escapa a la racionalidad del individuo. Algo que no está enteramente allá, pero tampoco acá, ni completamente dentro ni fuera de la (in)consciencia del sujeto que escribe. Con Oubiña, podemos ponderar esta subjetividad de los límites, siguiendo los trazos de la letra limpia y pura, frente a la mala palabra que enfatiza la naturaleza de desperdicio de la lengua, su "boca sucia," toda vez que las gramáticas no sólo establecen el uso correcto de la lengua, sino que, en su reverso, enuncian también lo incorrecto: 
Una vez prescripta la regla, se convalida inevitablemente el desvío. Contra el sistema ordenado del bien decir (bendecido por la institución), las malas lenguas habilitan una capacidad de mutación en la escritura. Si lo que puede leerse es, también, lo que debe leerse, la mala lengua es moralmente reprochable: porque debería ser dicha de otra manera y, sin embargo, insiste en su inadecuación. De ahí su malicia y su perversión (2011:3).

La hablante de Noches de adrenalina confiesa, muchas veces como extrayendo las notas tachadas o eliminadas de su diario íntimo -"elimino de este diario una dulce experiencia” (59), que la suciedad ha llegado a ser un capítulo de su existencia:

La suciedad llega a ser el capítulo de mi existencia

que resiste a la lucidez del adulto, el momento en que al levantarme la falda sobrevino el castigo el miedo a la soledad resbalar en el sueño de lo imaginado embriagado por sus propios olores (...)

lo obsceno sigue siendo para mí una prolongación de la incertidumbre

(71)

Suciedad, desnudo, obscenidad, demuestran que en la mirada narcisista se articula esa prolongación de la incertidumbre, que puede leerse como la etapa de transición desde la niña-adolescente, que descubre su cuerpo en el tacto vergonzante e interdicto de la masturbación -"después de masturbarme quería llorar de miedo y de verguienza" (67)-, a la mujer del presente que busca reconocerse en la imagen del cuerpo desnudo de la mujer adulta. En un proceso de transición que logra captar el objeto de la fantasía sexual de esta mujer que se autoindaga mediante la "mística" del cuerpo orgánico y sus fluidos, y que, a la postre, percibimos como un compendio atomizado de esa misma experiencia, donde, incluso, un sentimiento como el amor es asimilado o absorbido por ella, vuelto equivalente a la suciedad. El amor, parece decir Ollé, es todo lo que entra y sale del cuerpo, pero también todo lo que activa, en la relación cuerpo-mente, su psicología y funcionamiento integral:

AMOR - suciedad de las partes - regocijo de los genitales ¿nuestros hermosos vacíos son de índole melancólica?

o bajas de presión - elevación de temperatura - aceleración

del pulso - oh materia fisiológica - orgánica del despertar: aliento seco y ácido - topología de sufrir inflamaciones hepáticas - filosofía del morir: nostalgia que rebalsa la noche y su dinámica -embolia-abandono-ancianos 


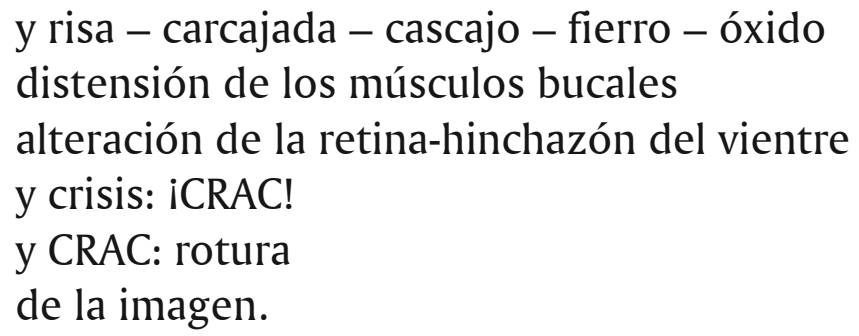

El poema condensa la visión cruda y descarnada frente a los procesos fisiológicos (emisiones del cuerpo: heces, orina, menstruación, menopausia) y psicológicos (nervios, melancolía, depresión), que enfrenta la voz poética desde un cuerpo y una psicología de mujer, en correspondencia con el proceso psico-auto-analítico de la "transferencia" de los deseos reprimidos:

camino, palpo el tubérculo de los recuerdos

mi cuerpo de niña

de la pureza

$$
\text { el silencio rígido }
$$

nada de entonces puede penetrarme del miedo

como esta ciudad en la usura.

(36)

En una suerte de monólogo dramático, donde el interlocutor es el propio yo desdoblado de la poeta-hablante-narradora, su alter ego ficcional, el "desvelo del cuerpo" desprovisto de toda idealidad conlleva al conocimiento del vacío de la existencia, al fortuito encuentro de la totalidad con el fragmento (Espina 1993), de acuerdo con una mirada que, así como sugiere el temor al horror vacui, a esa construcción del ser frente a la nada (en la cita intertextual con Sartre en su Ser y la Nada), al mismo tiempo fascina y conmociona. De allí que la mascarada de la mujer "teatrera" en su tendencia al fingimiento haga escritura el acto de lo obsceno (el espejo como objeto simbólico), que también sirve de espéculo a la poeta para ver su otro yo, su "otra mujer" -"abro mi fantasía y la encuentro deliciosa/gozo su cuerpo como otra mujer/esta mujer es mi rival" (62)-; la imagen narcisista que se desoculta en un movimiento imaginario de "desafío a lo real" cuando representa lo más real que lo real, lo hiperreal, "más verdadero que lo verdadero, como la simulación” (Baudrillard 1997), o como la desnudez:

Me es preciso salir y abandonar estos recuerdos de la

Infancia

Escoger una palabra que defina un ánimo invadido de sopor

El tedio es esta inmovilidad para pensar

En algo menos que nosotros

Escojo la desnudez. 
No puedo contemplarla sino gracias al espejo o en sus ojos

En su mirada excitada que indica una curva

Un viraje de la cintura hacia las nalgas

Un lomo erecto y soy la que se mueve alrededor de su eje

Mientras el reflejo que me brinda no me pertenece

La hablante se encuentra en un estado de crisis existencial -"y crisis: iCRAC!/y CRAC: rotura de la imagen” (41)-, que determina una autoestima más bien baja, producto de una autovaloración negativa que tiende a destacar los síntomas de la neurosis y la aflicción, el resquebrajamiento de su yo interior, en una situación de duelo en que este se experimenta como pobre y vacío. No olvidemos que en la melancolía hay una acuciante franqueza que se complace en el desnudamiento de sí mismo, al tiempo que el predominio de una disposición narcisista:

el espejo no sólo destruye lo que el tiempo

ante sus puertas observo mi vestido

ego erectus para mis pretendientes

(...)

el gesto neurótico frente al espejo es la épica

de una persona sin fortuna

el vestido es metáfora

(39)

Pero si el gesto neurótico frente al espejo es la épica y el vestido es metáfora de una identidad de género socialmente construida, el desnudo es el gesto obsceno por excelencia, cuando extrema el principio de lo visible por la absorción que contiene la energía de su contrario, lo oculto. Pero la desnudez en Ollé no es solo un hecho que oblitera el pasado de la infancia-adolescencia, en su intento por conjurar el recuerdo de esos años, sino también aquello que marca la imposibilidad del autoconocimiento actual en el presente de la escritura y la práctica del autoanálisis. Pese a ello, entremezclando la voz propia con aquellas apropiadas de sus lecturas teórico-literarias, logra desnudar a su alter ego: "fui masoquista/a solas gozadora del llanto en el espejo del WC/antes que La muerte de la familia nos diera el alcance" (14), con una cita de Bataille:

La desnudez de los senos, la obscenidad del

sexo, tienen la virtud de operar aquello con

lo que la niña, no ha podido más que soñar,

sin poder hacer nada

Esto nos recuerda al Freud de El malestar en la cultura, cuando se refería a la relación entre el proceso civilizador de la higiene y la evolución de la líbido en 
el individuo. Y al pasaje de Noches de adrenalina, en que la voz poética sostiene una suerte de aforismo-moraleja, mediante el uso del oxímoron, que (re) elabora su propia teoría sobre el tópico de la limpieza, prescrita por la higiene:

El que más se lava es el que más apesta como los buenos

olores son testimonio de una mala conciencia

como el grito es la figura de la timidez.

Irónicamente, reflexiona sobre la condición social de la limpieza cuando lo suyo es el aprendizaje vital, pero también estético-cultural, de la suciedad; ese aprendizaje que estará siempre en tensión con el orden civilizatorio, que establece Freud dentro de la "evolución" de la líbido humana. Ollé polemiza con esa pulsión de la limpieza, que no es solo del cuerpo sino también del imaginario, como un verdadero lastre histórico que moviliza una cierta higienización de la moral, del pensamiento, de las costumbres religiosas, del ethos social, en última instancia. Tratándose de un contrapunto entre el discurso socializado de la limpieza, que sostiene la sociedad "evolucionada" en sus regímenes de control de las sexualidades, el deseo y el placer, frente a lo obyecto que sitúa el lado puramente instintivo, "bárbaro", de la líbido humana, pero que en Noches de adrenalina sitúa a la suciedad como posibilidad introspectiva de conocimiento y deseo ilimitado del cuerpo en la adultez. La posibilidad de que el cuerpo oculto se abra y se exprese en el lenguaje de lo sucio por intermediación de "las verdades que dice la boca y las que silencian sus partes" (Villacorta 2008: 117); porque siempre es una boca la que habla, aunque el sonido deje de ser el ruido de un cuerpo como pura oralidad para convertirse en manifestación de un sujeto que se expresa (Deleuze 1989: 188).

Esa relación no se sustrae, entonces, al principio civilizador, evolutivo, del impulso sexual, pero tampoco deja de estar tensionada por la autopercepción y la mirada narcisista de la mujer que se autoindaga; más bien, enfatiza la función psíquica de la "transferencia" o la "cura psicoanalítica", mediante la cual el sujeto transfiere inconscientemente antiguos sentimientos, afectos, expectativas o deseos reprimidos para revivirlos en el presente. En Ollé, claramente se trata de una repetición de prototipos adolescentes, que se reviven con un marcado sentimiento de actualidad, mas no en relación con un interlocutor real, sino con el alter ego desdoblado de la poeta que actúa en función del analista:

viaje sin culminación en el que me abandono a la pasión del otro y en un juego de espejos transfiero el deseo al cuerpo que nos toca babeo porque babea y me pierdo en el scherzo delicioso de ser el que mira y el doble placer de ser el objeto que se mira. 
El subconsciente de la hablante no responde a las exigencias de "limpieza, orden y belleza" que "ocupan una posición particular entre las exigencias culturales" (Freud 37), porque el hecho de que esta triada opere de modo manifiesto revela que no es la suciedad la que debe representar un problema desde el punto de vista histórico, sino mas bien la compulsión a lo limpio (Laporte 1988: 19). Y es esa tensión, finalmente, del aprendizaje de la suciedad $\mathrm{v} / \mathrm{s}$ la limpieza la que activa los signos del duelo-melancolía, la neurosis y las pulsiones narcisistas, del sujeto poético de Noches de adrenalina. Así lo entiende Villacorta cuando afirma que a partir de la relación limpieza/suciedad se module la identidad de quien habla en el poema.

\section{El aprendizaje del cuerpo y la suciedad}

Como dialogando con Artaud en "La búsqueda de la fecalidad": "Hay en el ser/algo particularmente tentador para el hombre,/y ese algo es precisamente/ la caca", Ollé responde escribiendo la abyección, en el sentido psicoanalítico más primario:

Nuestro tótem

defecamos con soltura y es el único motor intacto

se corona una era escatológica

LA CACA ES TAN PODEROSA COMO UN PEQUEÑO COMPLEJO

¿Pero de qué civilización, estado de la cultura, es tótem "la caca” para Ollé?. La poeta alude a la fecalidad artaudiana para conjurar el universo de los desechos orgánicos del cuerpo, en que una pulsión ritual y conectora entre la lengua y el cuerpo, entre la inscripción y la carne, permea la visión de ese cuerpo producido o "doble cuerpo entreabierto", anatómico y textual, lacerado o mutilado, que moviliza su propia escritura. Una "escritura de retrete", por tanto, como "escatológica de la letra", donde se valida lo que "brota de natural de un cuerpo aplastado" y que "no se resume en fáciles categorías como divino o decadente" (Oubiña 2011: 17), sino en frases tajantes que diagnostican las condiciones exploradas en las dimensiones físico-psicológicas del cuerpo femenino:

Temía el olor del óvulo descompuesto al llegar el último día del menstruo el olor de un parte sucia y preservada así hace arder su repugnancia la pestilencia atrae las partes son el estado de su uso el en sí absoluto humores que se extinguen con lejía y cera 
en la mañana limpia y bañada

(...)

La función de la vergüienza es preservarnos de la vergüienza

de la función de una parte velluda y húmeda

una ascética frente a la que se deposita el ridículo

(38)

"La caca nueva y desconocida recobra su poder" (61), ¿poder de perversión?. He aquí el sentido de la abyección -aunque la mierda escrita huela menos, como señalaba Barthes-, que ironiza las condiciones culturales por las cuales la "cloaca máxima" del "Estado moderno" (Laporte 1988) ordena y purifica las gramáticas del habla y la escritura; el poder del discurso, en suma, que discrimina entre sujetos de habla, autorizados o no para articular la palabra, porque, como bien sostenía Foucault: "Se sabe bien que no se tiene derecho a decir todo, que no se puede hablar de todo en cualquier circunstancia, que cualquiera, en fin, no puede hablar de lo que sea..." (11). Ollé, sin embargo, se arroga ese derecho a decirlo todo y sin desparpajos, mas siempre desde la voluntad autoconciente y reflexiva de las palabras, que muchas veces toman la forma de sentencias filosóficas o, al decir de Reisz, de dicciones epigramáticas levemente autoparódicas:

Todo WC es un jardín oculto

Oler a orín reconforta

El cristianismo lleva hoy el peso de estos olores

Y muchos gramos de bicarbonato para las náuseas.

(23-4)

De este modo, si hay un vínculo estrecho entre higiene y gramática, en cuanto el ideal de limpieza y el de una lengua pura se cruzan en el poder del Estado, que jerarquiza las funciones del habla y las del cuerpo, el tratamiento estético de la abyección en Ollé desarrollará una retórica de la suciedad de las partes bajas del cuerpo, como un poder-saber de mujer, y del discurso, cotidiano y micropolítco; de donde la higiene estará siempre atravesada por lo sexual y excrementicio: -"vagina y ano se aproximan igual que placer/y desesperación en el momento de compartir la soledad" (37).

En otro pasaje que suelda esa escatológica de la letra por lo sexualexcrementicio, nos encontramos con la correspondencia más directa entre estos dos procesos:

me detuve en un hotel para hacer el amor.

Bella palabra hacer $=$ poiesis

se hace un verso el amor y la caca por algo de juego

natural

este hacer no necesita patente. 
Eros no solo se interconecta con el lenguaje y los traslapes de la creación poética, sino que también polemiza con estos quehaceres, toda vez que hacer el amor, escribir y defecar tienen el mismo sentido creativo y sensorial: "la poiesis fisiológica se acerca a la poiesis universal del éxtasis, el placer que producen estas tres actividades naturales" (Zapata 176). Placer y dolor -"es necesario el dolor para alcanzar placer" (43) -por medio de los desechos orgánicos, instalan la gramática del cuerpo y sus goces; no la limpieza, ni el régimen de la belleza consagrada, sino las fugas del orden civilizatorio del deseo y la sexualidad.

¿Y de dónde viene esa abyección de suciedad?, se pregunta Artaud, antes de arguiir que "allí donde huele a mierda, huele a ser". Mientras Ollé se pregunta si ¿el amoníaco de los pañales no es la lírica del orín?...

En Noches de adrenalina, la abyección va a persistir no solo como exclusión o tabú (nombrar la menstruación, el orgasmo, las deposiciones, etc.), y, en tanto que tal, como transgresión de la ley, sino también como acto de poder en la posibilidad de articular un discurso, que debe sortear antes la prueba de expropiación y apropiación de la palabra (ajena y propia). Ollé hace suya la palabra de teóricos y escritores como Bataille, Bachelard, Marx, Steiner, Safo, Komachi, entre otros, para producir su propia máquina de habla, y desde allí elaborar la dicción de su gramática deconstructiva por el aprendizaje de la suciedad. La poeta-narradora se apropia, así, de la palabra del otro para rearticular un poder (la de su propia escritura, la de su propio cuerpo) como otra forma de conocimiento, de poder/saber otro, quizás, en el más amplio sentido de la rebelión psicológica, como violencia y exceso en relación a una norma (moral, religiosa, social):

perdí miedo a mis ovarios

a la ceguera que amenazaba el contrariarlos

la temblorosa prosa del ano cedió a sus asedios

sólo quedó una leve mancha sobre la sábana

como una flor de goma

el amarillo mensual en la piel

$\mathrm{y}$

... el grano en la frente

por los que soy descubierta

los ovarios oprimen a la hora de labor

y el rostro pierde brillo por su neuralgia

(65)

Palabra y cuerpo se hacen uno en esta necesidad exploratoria de liberar el deseo de lo prohibido; se hacen pulsión ritual que despliega la posibilidad de anular, en sentido psicoanalítico, el o los fantasmas que este yo elucida en su experimentación-conocimiento-aprendizaje del cuerpo y sus partes 
sucias -"y mis partes están irritadas con fluidos verduscos/como tonos impresionistas" (36)-; cumpliéndose en ello una de las funciones éticas del psicoanálisis, cual es la de conducir al sujeto a que su discurso se acerque al "máximo de excitabilidad, "que la domine y la metabolice" (Kristeva 2002: 16). Porque esta operación, clave para el proceso de hacerse un discurso, un cuerpo de pensamiento, se actualiza en cada cuerpo material en relación con los instintos (el impulso deseante) que le abren camino. Solo de esta forma es posible para el sujeto poético de Ollé construir una subjetividad diferenciada, intimista y fetichista, que limita con los bordes de sus propias contradicciones desplegadas, sus espacios atomizados de perversión, sus grietas adosadas al poder de la palabra que se busca y no se encuentra, al poder de mostración de una identidad autoconstruida por lo fluido y el flujo, de la escritura y el propio cuerpo:

el pensamiento y el flujo: estoy agotada aquí en espera del ritual la retención de las ideas corresponde a los flujos reprimidos

\section{Para finalizar}

La construcción de un cuerpo producido, anatómico y textual, o, lo que es lo mismo, la anatomía/textualidad de un discurso de saber-poder otro, resulta clave para entender la noción misma de poder en Noches de adrenalina, en primer lugar, como el ejercicio de nombrar lo interdicto por los códigos de la norma moral y religiosa; y, en segundo, de transgredir los tabúes del cuerpo femenino con sus fluidos naturales y proceso de envejecimiento. El poder del discurso en la escritura de Ollé equivale a un acto de habla como posibilidad de hablar de sí misma y no a los 80 años, sino a los 30, cuando lo verdadero es el habla y no la espera, cuando el acto de habla no es trascendencia, sino puro cuchicheo intermitente e inútil, una teoría nerviosa de la historia:

la ciencia se vuelve bélica y hablar de sí mismo

no es nada práctico pero es una guerra

esperar a tener 80 años para hablar de sí mismo

¿dónde radica lo verdadero en esperar o en hablar?

(...)

Estoy en el Mediterráneo.

Podría estar en cualquier otro lugar sintiéndome

la misma criatura insólita y sorprendida ante los cambios de su cuerpo 
la traslación de un cuerpo significa un corte se vuelve a ser y lo que nos ocurre aquí no nos hubiera ocurrido allí.

Se cree esto con tanta fuerza con tan absoluta confianza que el regreso se nos figura un retorno a la frescura de la piel:

los dientes no se pudren allí

el rostro no se aja

la piel no pierde lustre.

Los parientes fallecen (porque hemos partido)

el pueblo estalla

las familias empobrecen

se repueblan se sintetizan

¿no es una teoría nerviosa de la historia?

(20)

De cara a las demandas por una agencia política de género, Ollé asume el flanco del grito y no la voz en sordina, cuando sabe que hablar de sí misma, más desde un cuerpo-pensamiento-mujer, "no es nada práctico pero es una guerra". Y puede ser que no ganara la guerra, pero sigue siendo una batalla del cuerpo y de la voz enfrentada a los poderes del discurso hegemónico, dominante o, más bien, a los discursos del Poder. Por eso hablamos del poder de la palabra y del discurso que se busca poseer como la trinchera desde la que Ollé da la batalla. Poeta, narradora, antes que todo lectora, decide poner en obra la noción de texto y escritura como una performance, donde el cuerpo de la voz es también el cuerpo de la mujer adulta mirándose a sí misma en el espejo psicoanalítico del "superyó", aquella instancia enjuiciadora de la actividad psíquica, donde se internalizan las normas y prohibiciones del tótem. Pero el espejo por el que se mira esta mujer es también aquel en cuyos reflejos se filtra la mirada distorsionada del recuerdo de su otro yo desdoblado, que induce el engaño de los sentidos; allí, donde a fuerza de mirar sus máscaras en el espejo la hablante ya no puede reconocer la imagen real (y actual) de su propio rostro y su propio cuerpo, en el momento presente en que la mirada se filtra por ese otro espejo ficcional de la escritura.

\section{Referencias bibliográficas}

BATAILLE, Georges (1977): La literatura y el mal. Madrid, Taurus.

BAUDRILLARD, Jean (1997): Las estrategias fatales. Barcelona: Anagrama.

DELEUZE, Gilles (1989): Lógica del sentido. Barcelona, Paidós.

ESPINA, Eduardo (1993): "Poesía peruana: 1970, 1980, 1990". Revista iberoamericana 164-165; pp. 687-702. 
FOUCAULT, Michel (1992): El orden del discurso. Madrid: Tusquets.

FREUD, Sigmund (1991): El malestar en la cultura. Madrid: Alianza.

KRISTEVA, Julia (2006): Poderes de la perversión. Buenos Aires: Siglo XXI. (2002): Al comienzo era el amor. Psicoanálisis y fe. Barcelona: Gedisa.

LAPORTE, Dominique (1988): Historia de la mierda. Valencia, Pre-textos.

MAZZOTTI, José Antonio y Zapata, Miguel Ángel (1995): El bosque de los huesos. Antología de la Nueva Poesía Peruana 1963-1993. México: El Tucán de Virginia.

MIRANDA, Sylvia (2008): "Poesía y novela: el París de Carmen Ollé”. Anales de Literatura Hispanoamericana 37; pp. 275-285.

MORALES Saravia, José (2008): "Poéticas emergentes de la poesía peruana”. Hymen 5; pp. 119-157.

OLLÉ, Carmen (2005): Noches de adrenalina. Lima: Flora Tristán-Lluvia Editores.

OUBIÑA, David (2011): "Osvaldo Lamborghini: la lengua larga y la boca sucia” en El silencio y sus bordes. Modos de lo extremo en la literatura y el cine. Buenos Aires: FCE.

REISZ, Susana (1996): Voces sexuadas. Género y poesía en Hispanoamérica. Lleida: Asociación Española de Estudios Literarios Hispanoamericanos.

RICHARD, Nelly (1990): "De la literatura de mujeres a la textualidad femenina”. Escribir en los bordes: Congreso Internacional de Literatura Femenina latinoamericana 1987. Carmen Berenguer et alii (compiladora) Santiago de Chile: Cuarto Propio; pp. 25-32.

ROWE, William (1996): Hacia una poética radical. Ensayos de hermenéutica cultural. RosarioLima: Beatriz Viterbo-Mosca Azul Editores.

VILLACORTA, Carlos (2008): "Erotismo y espacio en Noches de adrenalina de Carmen Ollé: una lectura de Bataille y Bachelard”. INTI 67-68; pp. 117-126.

ZAPATA, Miguel Ángel (2002): "Anatomía y textualidad en la poesía de Carmen Ollé", en Moradas de la voz. Notas sobre la poesía hispanoamericana contemporánea. Lima: Universidad Nacional Mayor de San Marcos; pp. 105-120. 